British prisons where $40 \%$ of the inmates have serious drinking problems. One would also have to compare very unfavourably our overcrowded prisons and Mr Douglas Hurd's hope that the practice of 'slopping out' may cease in three years' time, with the situation in the prisons of Lower Saxony. Here, although the number of prisoners has been reduced this year from 6,041 to 5,072 , the number of cells has increased from 5,887 to 6,093 , the extra cells being used for recreation, hobbies and visits (Remmers, 1989). Most of the cells have their own toilets. Indeed many of our patients claim they would rather be in gaol than in hospital, as they have found the former more comfortable. I, on the other hand, have seldom seen such a well-appointed hospital.

In general the German system cares for its forensic patients flexibly, leniently and well. Baron von Münchhausen expected his audience to be broadminded. Perhaps like that audience, we too could broaden our minds and consider other ways in which we could offer assistance to some of the more disadvantaged members of our society. Certainly we could improve our facilities.

\section{Acknowledgement}

I should like to thank Dr med Martin Schott, Medizinischer Direktor, Landeskrankenhaus, Moringen for his comments and advice.

\section{References}

LANGELÜDDEKE, A. \& BRESSER, P. H. (1976) Gerichtliche Psychiatrie. Berlin, New York: Verlag W. de Gruyter.

KocH, G. (1988) Katamnese bei suchtkranken Straftätern nach bedingter Entlassung aus dem Massregelvollzug. Medizinische Hochschule, Hanover.

Rasch, W. (1986) Forensische Psychiatrie. Stuttgart, Berlin, Cologne, Mainz: Verlag Kohlhammer GmbH.

REMMERS, W. (1989) Justizminister, Landesregierung, Niedersachsen.

Strafgesetzbuch In statute from 2 January 1975.

\title{
Psychiatric presentations to an accident and emergency department
}

\author{
John Dunn, Senior Registrar, Department of Psychological Medicine, Hammersmith \\ Hospital, Du Cane Road, London W12 (correspondence); and RENUKA FERNANDO, \\ Clinical Assistant, Pembury Hospital, Tunbridge Wells, Kent
}

The nature, management and disposal of patients who present to casualty departments and receive psychiatric diagnoses by the assessing doctor are areas that have received scant attention by psychiatric researchers. The aim of this study was to analyse the records of such patients to see how they had been managed, in particular to document the degree of psychiatric intervention provided or offered, and to see what follow-up arrangements, if any, had been made.

\section{The study}

The hospital studied is located at the northern tip of its catchment area. It serves one of inner London's poorer boroughs and is close to a major train terminal. It has a busy casualty department, where over
50,000 patients are seen each year. There are both psychiatric in-patient and out-patient facilities on site, with two further in-patient units in the north and south of the district. There is a resident on-call psychiatric registrar, who can be called to assess patients in the casualty department outside of hours. During the hours of 9 a.m. to 5 p.m. the same on-call registrar can be requested to see urgent psychiatric referrals from the casualty department in the outpatient department.

All the casualty cards for the first six months of 1986 were scrutinised $(n=25,651)$. Information was recorded only on those patients who were judged by the casualty officer or the duty psychiatrist to be suffering from a psychiatric disorder. Patients with a psychiatric history who presented with a physical problem were excluded. Patients intoxicated with 
TABLE I

Diagnoses and disposal of psychiatric patients identified in the casualty department. Numbers (percentages)

\begin{tabular}{lccccc}
\hline Diagnosis & Numbers (\%) & $\begin{array}{c}\text { Seen by } \\
\text { psychiatrist }\end{array}$ & $\begin{array}{c}\text { Admitted to } \\
\text { hospital }\end{array}$ & $\begin{array}{c}\text { Not admitted } \\
\text { but followed-up }\end{array}$ & No follow-up \\
\hline Deliberate self-harm & $180(39)$ & $119(66)$ & $117(65)$ & $36(20)$ & $27(15)$ \\
Alcohol misuse & $79(17)$ & $15(19)$ & $7(9)$ & $20(25)$ & $52(66)$ \\
Drug misuse & $28(6)$ & $8(29)$ & $5(18)$ & $11(39)$ & $12(43)$ \\
Psychosis & $49(11)$ & $36(73)$ & $18(37)$ & $24(49)$ & $7(14)$ \\
Affective disorder & $48(10)$ & $32(67)$ & $16(33)$ & $27(56)$ & $5(10)$ \\
Anxiety & $38(8)$ & $8(21)$ & $0(0)$ & $21(55)$ & $17(45)$ \\
Other & $42(9)$ & $22(52)$ & $5(12)$ & $23(55)$ & $14(33)$ \\
Totals & $464(100)$ & $240(52)^{*}$ & $168(36) \dagger$ & $162(35) \ddagger$ & $134(29)$ \\
\hline
\end{tabular}

${ }^{*} \chi$-squared $=97.7$ with 6 degrees of freedom, $P<0.001$.

t $\chi$-squared $=128.7$ with 6 degrees of freedom, $P<0.001$

$\mp \chi$-squared $=40.3$ with 6 degrees of freedom, $P<0.001$.

alcohol but who presented with a physical complication, e.g. a head injury, were also excluded. Deliberate self-poisoning, although initially treated by the medical teams, was classified as a psychiatric problem. Deliberate self-harm patients who were admitted to the short stay ward were routinely referred to the duty psychiatrist, but those who were not admitted were referred at the discretion of the casualty officer.

A standardised pro forma was used to collect data. Information was recorded on demographic variables such as age, sex, and address; the mode of presentation; the presenting complaint; psychiatric diagnosis; treatment and immediate disposal. The study was performed retrospectively and, since many casualty cards contained limited information, detailed psychiatric symptomatology, sufficient to make standard research diagnoses, was often not available. A pilot study enabled us to place all the psychiatric presentations under one of the following headings: deliberate self-harm, alcohol misuse, drug misuse, psychosis, affective disorder, anxiety, and other (including personality disorder, amnesia, dementia, trans-sexualism and no diagnosis).

The data were entered onto a MINITAB computer programme. Statistical comparisons were made using the $\chi$-squared test.

There were 25,651 casualty attenders during the first six months of 1986; of these $464(1.8 \%)$ were judged to be suffering from a psychiatric disorder at the time of presentation. The mean age of this group was 34 years (standard deviation \pm 14 years) and approximately half were under the age of 31 . There were $257(55 \%)$ men and $207(45 \%)$ women. The majority of these patients either lived outside of the hospital's catchment area $(227,49 \%)$ or were of no fixed abode $(68,17 \%)$. Two hundred and twenty-one patients $(48 \%)$ were brought to casualty by ambu- lance, while $209(45 \%)$ walked in. Only 17 patients (4\%) brought a letter of referral from their GP.

Patients presented to casualty throughout the day, but most commonly in the evenings: $131(28 \%)$ arrived between 9 a.m. and 5 p.m.; 207 (45\%) between 5 p.m. and 12 midnight; and 125 (27\%) between 12 midnight and 9 a.m. The percentage presenting each day of the week did not vary greatly, about $15 \%$ per day with the exception of Sunday $(10 \%)$.

Table I shows the psychiatric diagnoses given to the patients. The majority of patients were seen by a psychiatrist $(240,52 \%)$ and a further $26(6 \%)$ were referred but did not wait to be seen. There were significant differences between diagnostic groups on their likelihood of being seen by a psychiatrist, $P<0.001$ (Table I).

Only a small number of patients were prescribed psychotropic medication (52, 11\%). Patients performing acts of deliberate self-harm, psychotic patients and those suffering from affective disorders were more likely to be admitted to hospital than patients in other diagnostic groups, $P<0.001$ (Table I). Of those patients who were not admitted to hospital, over one-third were given an immediate, urgent or non-urgent out-patient appointment and just under one half were discharged from casualty without follow-up. Offers of follow-up related to diagnostic category and once again these differences were statistically significant, $P<0.001$ (Table I).

\section{Comment}

Of the total number of patients presenting to this casualty department, $1.8 \%$ were considered to be suffering primarily from a psychiatric disorder. This is almost certainly an underestimate of the true prevalence of psychiatric disorder. Such disorders 
may present with physical complications, e.g. haematemesis secondary to alcohol misuse; secondary to physical illness, e.g. cancer and depression; or coincidentally with physical illness. These types of presentation would tend to be missed or excluded from this study. Two other studies of London casualty departments reported similar prevalence rates for psychiatric disorder, 2.2\% at Guy's Hospital (Anstee, 1972) and $2.5 \%$ at Kings College Hospital (Watson, 1969).

Whether patients who presented to our casualty department with psychiatric problems were 'true emergencies' or just 'casual attenders' (Fry, 1960) is not a question that can easily be answered by a retrospective study. However, certain indices, such as mode of arrival and immediate disposal, might give one a measure of the appropriateness of this route of presentation. Forty-five per cent of patients were brought to hospital by ambulance and $37 \%$ were admitted. If one excludes those patients who had performed an act of deliberate self-harm, for whom the notion of being an emergency is at least more tangible, $38 \%$ were brought to hospital by ambulance and $18 \%$ were admitted. A survey of another London casualty department revealed that $39 \%$ of new general referrals were neither accidents nor emergencies and $67 \%$ were self-referrals who had not previously seen their general practitioner (Davison et al, 1983). Clearly the open door policy of accident departments leaves them open to misuse by general and psychiatric patients alike.

From the results of this survey it is clear that the degree of intervention offered to patients with psychiatric problems is dependent on the nature of the presenting complaint. Patients who were psychotic, suffered from affective disorders or had deliberately harmed themselves were usually assessed by a psychiatrist and were often admitted to hospital or offered out-patient follow-up. That is not to say psychiatric intervention was offered to all patients with disabling, distressing or treatable conditions. Of all the diagnostic categories described, patients labelled 'alcohol misusers' received the least intervention, despite their problems having severe physical, psychological and social sequelae. It must be said that many of these patients were acutely intoxicated at the time of presentation, some were abusive and many were not requesting psychiatric help. However, one-third were either in a withdrawal state or were requesting detoxification, and one-third were under the age of 25 years, i.e. early on in their drinking careers. It has been argued that more help should be offered to alcohol misusers, even if they are intoxicated at the time of presentation (Healy, 1988).

Self-referral to specialists has been criticised (Williams, 1988) and casualty departments are places where this can easily occur (Jones \& McGowan, 1989). Few of our patients were referred by a general practitioner, yet an increasing number of GP trainees undertake vocational training in psychiatry. However, the majority of our patients presented outside of normal working hours or at weekends, when a visit to the local casualty department might be considered preferrable to calling out the emergency doctor who may be an unfamiliar deputising doctor. A study at another London casualty department revealed that $12 \%$ of patients were not registered with a GP (Davison et al, 1983); for such patients there may be no alternative but the casualty department. But if many of our patients were not 'true emergencies' should they have been attending the casualty department at all? Again this depends on whether there is an alternative. Fully staffed psychiatric emergency clinics or community mental health centres which are open 24 hours a day are very few and even farther between. Rather than reproach patients for overusing what is an effective service we should be aiming to expand these alternatives. They should aim to be as flexible, accessible and free of stigma as casualty departments are and to undertake assessments without undue delay and have easy access to a specialist. For many patients casualty departments will continue to provide this service.

\section{References}

ANSTEE, B. H. (1972) Psychiatry in the casualty department. British Journal of Psychiatry, 120, 625-629.

DAvison, A. G.; HiLDREY, A. C. C. \& FLOYER, M. A. (1983) Uses and misuses of an accident and emergency department in the East End of London. Journal of the Royal Society of Medicine, 76, 37-40.

FrY, L. (190) Casualties and casuals. Lancet, i, 163-166.

HEALY, K. (1988) Assessment of drunk patients. Bulletin of the Royal College of Psychiatrists, 12, 104-105.

JONES, C. S. \& MCGOWAN, A. (1989) Self-referral to an accident and emergency department for another opinion. British Medical Journal, 298, 859-862.

Watson, J. P. (1969) Psychiatric problems in accident departments. Lancet, i, 877-879.

Williams, G. (1988) Self-referral to consultants. British Medical Journal, 296, 861. 